\title{
The prognostic value of different glucose abnormalities in patients with acute myocardial infarction treated invasively
}

Michal Mazurek ${ }^{1 *}$, Jacek Kowalczyk', Radoslaw Lenarczyk', Teresa Zielinska', Agnieszka Sedkowska', Patrycja Pruszkowska-Skrzep ${ }^{1}$, Andrzej Swiatkowski ${ }^{1}$, Beata Sredniawa', Oskar Kowalski', Lech Polonski², Krzysztof Strojek ${ }^{3}$ and Zbigniew Kalarus ${ }^{1}$

\begin{abstract}
Background: Diabetes (DM) deteriorates the prognosis in patients with coronary heart disease. However, the prognostic value of different glucose abnormalities (GA) other than DM in subjects with acute myocardial infarction (AMI) treated invasively remains unclear.
\end{abstract}

Aims: To assess the incidence and impact of GA on clinical outcomes in AMI patients treated with percutaneous coronary intervention (PCI).

Methods: A single-center, prospective registry encompassed 2733 consecutive AMI subjects treated with PCl. In all in-hospital survivors ( $n=2527,92.5 \%$ ) without the history of DM diagnosed before or during index hospitalization standard oral glucose tolerance test (OGTT) was performed during stable condition before hospital discharge and interpreted according to WHO criteria. The mean follow-up period was 37.5 months.

Results: The incidence of GA was as follows: impaired fasting glycaemia - IFG $(n=376,15 \%)$; impaired glucose tolerance - IGT ( $n=560,22 \%)$; DM ( $n=425,17 \%)$; new onset DM $(n=384,15 \%)$; and normal glucose tolerance - NGT $(n=782,31 \%)$. During the long-term follow-up, death rate events for previously known DM, new onset DM and IGT were significantly more frequent than those for IFG and NGT (12.3; 9.6 and 9.4 vs. 5.6 and 6.4\%, respectively, $\mathrm{P}<0.05)$. The strongest and common independent predictors of death in $\mathrm{GA}$ patients were glomerular filtration rate $<60 \mathrm{ml} / \mathrm{min} / 1,73 \mathrm{~m} \wedge 2$ (HR 2.0 and 2.8) and left ventricle ejection fraction $<35 \%$ (HR 2.5 and 1.8, all $\mathrm{P}<0.05)$ respectively.

Conclusions: Glucose abnormalities are very common in AMI patients. DM, new onset DM and IGT increase remote mortality. Impaired glucose tolerance bears similar long-term prognosis as diabetes.

Keywords: Acute myocardial infarction, Glucose abnormalities, Diabetes mellitus, Percutaneous coronary intervention

\section{Introduction}

The prevalence of type 2 diabetes mellitus (DM) has rapidly increased worldwide over the last decades and DM is increasingly perceived as an ongoing epidemic. There is a conclusive evidence implicating DM in complications of coronary heart disease (CHD) [1], [2], [3]

\footnotetext{
* Correspondence: m.i.c.h.a.l@wp.pl

'Department of Cardiology, Congenital Heart Diseases and Electrotherapy, Medical University of Silesia, Silesian Center for Heart Diseases, ul. Szpitalna 2, 41-800 Zabrze, Poland

Full list of author information is available at the end of the article
}

and [4]. The risk of acute myocardial infarction (AMI) and death in diabetic subjects without CHD is similar to the risk of non-diabetic pts with previous AMI. Therefore, DM has gained the status of CHD risk equivalent [5]. Despite recent treatment improvements of AMI, patients with DM have worse prognosis after myocardial infarction in comparison to subjects without DM. There is also evidence that CHD patients have glucose abnormalities (GA) other than DM. Mozaffarian et al. as well as Bartnik et al. compared population-based cohorts of patients with AMI and found that AMI groups showed 
almost twice higher annual incidence-rates of impaired fasting glucose and diabetes. Therefore, they proposed that myocardial infarction may be a prediabetes equivalent [6] and [7]. However, the early and long-term outcome in AMI patients with glucose abnormalities other than DM remains unclear. The aim of our study was to assess the incidence and prognostic role of different glucose abnormalities in AMI patients treated with percutaneous coronary intervention (PCI) as well as to identify independent predictors of death in GA.

\section{Materials and methods}

\section{Data acquisition}

A computerized database was used for prospective collection of data from 2733 consecutive patients admitted with AMI to our department. Recorded data included demographic and laboratory parameters, concomitant diseases, characteristics of AMI, types of glucose abnormalities, angiographic findings, outcomes of revascularization procedure, in-hospital complications and mortality. Data concerning longterm outcome was collected from a database of the National Fund of Health. The mean follow-up period was 37.5 months and the data was collected from $99 \%$ of patients enrolled in the study.

\section{Protocol of the registry}

The study population consisted of 2733 consecutive patients admitted to our Department with AMI and treated in the acute phase with PCI between January 2003 and December 2007. In all in-hospital survivors $(\mathrm{n}=2527,92.5 \%)$ without the history of diabetes mellitus diagnosed before or during index hospitalization standard oral glucose tolerance test (OGTT) was performed after stabilization of patients' condition, routinely the day before or on discharge day, however no sooner than on day 5. Results of OGTT were interpreted in line with WHO recommendations for GA diagnosis [8]. This measure made it possible to diagnose the following glucose abnormalities: IFG - impaired fasting glycaemia; $I G T$ - impaired glucose tolerance; $D M$ - diabetes mellitus diagnosed previously; new onset $D M$ - diabetes mellitus diagnosed during index hospitalization; and NGT patients with normal glucose tolerance. Patients with IFG and IGT comprised a prediabetic group, while subjects with both, previously diagnosed DM as well as with the new onset DM represented the diabetic group. The rest of the patients, without any glucose disturbances, constituted the NGT group [Figure 1].

\section{Measurements and definitions}

Diagnosis of glucose abnormalities was based on WHO criteria for venous plasma [8]. Patients were classified as having DM if they reported current or previous use of antidiabetic medications (insulin or oral hypoglycaemic agents). A new onset DM was diagnosed if fasting glycaemia during hospitalization, but no sooner than on day 5 was $\geq 7.0 \mathrm{mmol} / \mathrm{l}$ on at least two occasions $(17.7 \%$ of cases) as well as on the basis of OGTT if fasting glycaemia was $\geq 7.0 \mathrm{mmol} / \mathrm{l}$ or a two hour post-load glucose level $\geq 11.1 \mathrm{mmol} / \mathrm{l}$. OGTT made it possible to diagnose the new onset DM in $82.3 \%$ of cases. IFG was diagnosed if fasting glucose was $\geq 6.1$ but $<7.0 \mathrm{mmol} / \mathrm{l}$, and IGT if fasting glucose was $<7.0 \mathrm{mmol} / \mathrm{l}$ and postprandial glucose level $\geq 7.8$ but $<11.1 \mathrm{mmol} / \mathrm{l}$. Normal glucose tolerance group consisted of patients with fasting glucose $<6.1 \mathrm{mmol} / \mathrm{l}$, and $2 \mathrm{~h}$ post-load glucose level $<7.8 \mathrm{mmol} / \mathrm{l}$.

Clinical AMI criteria evaluated on admission were: chest pain persisting $>20 \mathrm{~min}$, ST segment elevation of at least $0.1 \mathrm{mV}$ in two or more continuous ECG leads or non-diagnostic ECG with enzymatic confirmation of AMI. The biochemical criterion of myocardial infarction was elevated troponin I above the upper limit of normal. The other biochemical markers of myocardial injury: creatinine kinase $(\mathrm{CK})$ and its isoenzyme $\mathrm{MB}(\mathrm{CK}-\mathrm{MB})$ were assessed in all subjects. Patients were mainly admitted from referral hospitals and previous administration of fibrinolytic treatment was allowed. No upper age limit was used.

Duration of chest pain was estimated by the time interval between chest pain onset and the time of arrival to the emergency room. Multivessel disease was defined as the presence of $>2$ major epicardial coronary arteries or their major branches with stenosis of at least $70 \%$, assessed during initial coronary angiography. Complete revascularization was defined when no total occlusion and no residual stenosis $>70 \%$ (for left main $>50 \%$ ) was found in any major coronary artery or their major branches at discharge.

The estimated glomerular filtration rate was calculated using serum creatinine value on admission before catheterization, according to the abbreviated Modification of Diet in Renal Disease Study Group Equation proposed by National Kidney Foundation. Contrast-induced nephropathy $(\mathrm{CIN})$ was defined as a rise in serum creatinine of $44.2 \mu \mathrm{mol} / \mathrm{L}(0.5 \mathrm{mg} / \mathrm{dL})$, or a $25 \%$ increase from the baseline value within $48 \mathrm{~h}$ after PCI [9].

\section{Treatment protocol}

In all consecutive patients, coronary angiography and PCI of infarct-related artery (IRA) were performed with the use of standard techniques immediately after hospital admission. All patients before coronary angiography received a single dose of oral aspirin (300-500 mg) and 5000-10000 U of intravenous heparin (additional boluses were given as appropriate to achieve activated clotting time $>250 \mathrm{~ms})$. The goal of PCI was to restore Thrombolysis in Myocardial Infarction (TIMI) 3 grade 


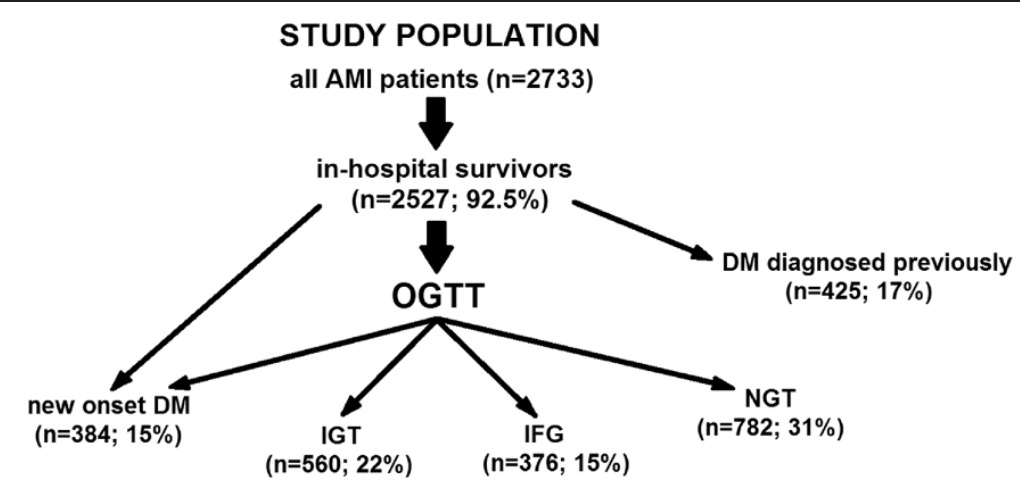

Figure 1 Study population selection, AMI - acute myocardial infarction, OGTT - oral glucose tolerance test, DM new onset - newly diagnosed diabetes mellitus, DM - diabetes mellitus diagnosed previously, IGT - impaired glucose tolerance, IFG - impaired fasting glucose, NGT - normal glucose tolerance.

flow with residual stenosis lower than 30\%, which denotes a successful procedure. After the intervention, all patients received $150 \mathrm{mg}$ of aspirin daily indefinitely, $300 \mathrm{mg}$ clopidogrel just before PCI, followed by $250 \mathrm{mg}$ ticlopidine twice daily or $75 \mathrm{mg}$ clopidogrel daily orally, as well as beta-blockers, ACE inhibitors/ angiotensin receptor blockers (ARB) and statins, if these agents had not been contraindicated.

Hypoglycaemic treatment in the acute phase of AMI was in line with the DIGAMI protocol [10]. In patients with DM and blood glucose $>11 \mathrm{mmol} / \mathrm{l}$ as well as in those without the previous diagnosis of DM, but with glucose levels over $11 \mathrm{mmol} / \mathrm{l}$ the insulin infusion was administered for at least $24 \mathrm{~h}$ followed by daily subcutaneous insulin injections for the remainder of the hospital stay and a minimum of 3 months thereafter. Every patient with the diagnosis of any type of GA was consulted by a diabetology specialist before hospital discharge and several issues with regard to lifestyle modification (body weight normalization, physical activity, smoking cessation), diet and medication were addressed.

\section{Outcomes}

The primary outcome was death from any cause. Secondary outcomes included one of the following events: either recurrent myocardial infarction, repeated PCI, coronary artery by-pass grafting or stroke. Major adverse cardiovascular event (MACE) was defined as the occurrence of death or any of the above during observation period.

\section{Statistical analysis}

Continuous parameters were expressed as means with standard deviations unless otherwise specified, categorical variables were presented as numbers and percentages. Comparative analysis between groups was performed using Student's t-test for continuous variables and Chi-square or Fisher's exact test, as appropriate, for dichotomous parameters. Log-rank tests were used to compare Kaplan-Meier curves plotted for cumulative survival and freedom from MACE. Independent predictors of death were identified with multivariate Cox-regression model and expressed as hazard ratio with 95\% confidence interval. Regression models were developed after the inclusion of all parameters with significant univariate association with appropriate end-point. All tests were double-sided. $P$ value $<0.05$ was considered statistically significant. All analyses were performed using the software package Statistica (version 6.1, StatSoft Inc., Tulsa, OK, USA).

The following variables were incorporated into the multivariate analysis model in order to identify independent predictors of death in different glucose abnormalities: age $>70$ years, gender, prior stroke, prior AMI, previous CABG, previous PCI, multivessel disease, Killip class and cardiogenic shock on admission, hypertension, hyperlipidaemia, smoking, symptoms duration, IIb/IIIa inhibitors, unsuccessful PCI of IRA (TIMI $<3$ after PCI), previous thrombolytic treatment, incomplete revascularization (ICR), glomerular filtration rate (GFR), contrast induced nephropathy (CIN), left ventricle ejection fraction (LVEF), type of AMI (NSTEMI vs STEMI), type of infarct-related artery (IRA), haematocrit, hemoglobin level.

\section{Ethics}

All clinical data was obtained as the result of diagnostic and therapeutic procedures, which were in line with treatment guidelines for myocardial infarction. All patients provided an informed, written consent for hospitalization, invasive treatment and the use of collected data for research purposes.

\section{Results}

Baseline characteristics

Patients with DM and IGT were older, with lower frequency of male gender and smokers, more often 
presented with hypertension, chronic kidney disease and contrast-induced nephropathy. What is more, they had higher Killip class and higher values of admission glycaemia as well as lower ejection fraction and glomerular filtration rate in comparison to IFG and NGT groups.

Diabetic patients presented also with longer symptoms duration, higher frequency of prior AMI, multivessel coronary artery disease, incomplete revascularization, as well as lower efficacy of PCI defined as TIMI flow $<3$ of IRA in comparison to other study groups.

The usage of beta-blockers, statins, ACE inhibitors/ ARB, acetylsalicylic acid, and clopidogrel/ticlopidine during in-hospital period and prescribed at discharge did not differ significantly between study groups [Table 1].

\section{Long term outcome}

Total mortality rate in the entire study population was $8.6 \%$. There were no differences in 30-day mortality between all study groups. However, during 1-year followup death rate events were significantly more frequent both in DM and IGT in comparison to IFG and NGT groups (9.0 and 6.7 vs. 2.9 and $3.7 \%$, respectively, $\mathrm{P}<0.05)$. Similarly, during the long-term follow-up, death rate events for previously known DM, new onset DM and IGT were also significantly more frequent than those for IFG and NGT groups (12.3; 9.6 and 9.4 vs. 5.6 and $6.4 \%$, respectively, $\mathrm{P}<0.05$ ) [Table 2].

Incidence of MACE was significantly higher in DM compared to other study groups in a 30-day follow-up.

Table 1 Comparative analysis of demographic, clinical and laboratory data among study groups

\begin{tabular}{|c|c|c|c|c|c|}
\hline Variable & $\mathrm{DM}(\mathrm{n}=425)$ & New onset DM $(n=384)$ & IGT $(n=560)$ & IFG $(n=376)$ & NGT $(n=782)$ \\
\hline Age (yrs) & $65.5 \pm 9.5^{*}$ & $65.3 \pm 10.4^{*}$ & $62.3 \pm 10.3^{*}$ & $58.2 \pm 11.0$ & $57.0 \pm 11.3$ \\
\hline Male - no. (\%) & $241(56.7)^{*}$ & $237(61.6)^{*}$ & $395(70.5)^{*}$ & $316(82.4)$ & $618(79.0)$ \\
\hline Smoking - no. (\%) & $166(39.1)^{*}$ & $182(47.4)^{*}$ & $319(56.9)^{*}$ & $245(65.1)$ & $533(68.2)$ \\
\hline Hypertension - no. (\%) & $320(75.3)^{*}$ & $218(56.9)^{*}$ & $302(53.9)^{*}$ & $167(44.3)$ & $325(41.6)$ \\
\hline Hyperlipidaemia - no. (\%) & $232(54.5)$ & $200(52.1)$ & $295(52.6)$ & $208(55.2)$ & $411(52.5)$ \\
\hline Peripheral vascular disease - no. (\%) & $42(9.9)$ & $41(10.8)$ & $48(8.5)$ & $23(6.1)$ & $61(7.8)$ \\
\hline Creatinine on admission ( $\mu \mathrm{mol} \mathrm{NL}$ ) & $104.3 \pm 86.6^{*}$ & $92.1 \pm 39.2^{*}$ & $85.9 \pm 34.0$ & $80.3 \pm 18.7^{*}$ & $85.5 \pm 42.5$ \\
\hline $\mathrm{GFR}\left(\mathrm{mL} / \mathrm{min} / 1.73 \mathrm{~m}^{2}\right)$ & $73.3 \pm 26.7^{*}$ & $77.6 \pm 25.6^{*}$ & $84.5 \pm 25.2^{*}$ & $92.5 \pm 24.5^{*}$ & $89.2 \pm 25.6$ \\
\hline Contrast-induced nephropathy - no. (\%) & $110(25.8)^{*}$ & $127(33.2)^{*}$ & $150(26.8)^{*}$ & $79(21.1)$ & $133(17.0)$ \\
\hline Previous myocardial infarction - no. (\%) & $113(26.5)^{*}$ & 75 (19.6) & $95(16.9)$ & $61(16.3)$ & $132(16.9)$ \\
\hline Previous PCI - no. (\%) & $63(14.8)^{*}$ & $31(8.2)$ & $54(9.6)$ & $26(7.0)$ & $66(8.4)$ \\
\hline Glucose on admission (mmol/L) & $12.2 \pm 5.4^{*}$ & $9.6 \pm 4.1^{*}$ & $7.8 \pm 2.5^{*}$ & $7.2 \pm 2.0$ & $7.2 \pm 2.2$ \\
\hline Pain duration (hours) & $7.9 \pm 9.9^{*}$ & $7.9 \pm 10.5^{*}$ & $5.8 \pm 6.6$ & $5.7 \pm 5.9$ & $5.9 \pm 7.4$ \\
\hline Killip-class on admission & $1.3 \pm 0.7^{*}$ & $1.4 \pm 0.8^{*}$ & $1.3 \pm 0.6^{*}$ & $1.2 \pm 0.5$ & $1.2 \pm 0.5$ \\
\hline Anterior infarction - no. (\%) & $144(33.8)$ & $150(39.1)^{*}$ & $195(34.8)$ & $143(37.9)^{*}$ & $242(31.0)$ \\
\hline Ejection fraction (\%) & $42.0 \pm 8.4^{*}$ & $42.8 \pm 8.3^{*}$ & $43.8 \pm 7.8^{*}$ & $44.9 \pm 7.7$ & $45.7 \pm 7.0$ \\
\hline Fibrinolysis - no. (\%) & $10(2.3)$ & $10(2.5)$ & $21(3.8)$ & $8(2.1)$ & $31(4.0)$ \\
\hline GP IIb/IIla - inhibitor - no. (\%) & $68(16.0)^{*}$ & $66(17.3)^{*}$ & $80(14.3)$ & $58(15.5)^{*}$ & $84(10.8)$ \\
\hline Beta-adrenergic blocker - no. (\%) & $372(87.6)$ & $338(88.1)$ & $498(88.9)$ & $327(87.0)$ & $702(89.8)$ \\
\hline ACE-inhibitor/ARB - no. (\%) & $369(86.9)$ & $328(85.4)$ & $483(86.2)$ & $320(85.2)$ & $672(85.9)$ \\
\hline Aspirin - no. (\%) & $414(97.4)$ & $376(98.0)$ & $549(98.0)$ & $369(98.2)$ & $769(98.3)$ \\
\hline Clopidogrel/Ticlopidine - no. (\%) & $369(86.9)$ & $335(87.2)$ & $488(87.1)$ & $325(86.4)$ & $683(87.4)$ \\
\hline Multivessel coronary artery disease -no (\%) & $322(75.8)^{*}$ & $252(65.7)^{*}$ & $346(61.7)$ & $222(59.1)$ & $456(58.3)$ \\
\hline Incomplete revascularization - no. (\%) & $240(56.5)^{*}$ & $177(46.1)$ & $264(47.1)$ & $172(45.8)$ & $328(41.9)$ \\
\hline TIMI flow <3 after PCI of IRA - no. (\%) & $63(14.9)^{*}$ & $70(18.1)^{*}$ & $72(12.8)$ & $45(12.1)$ & $77(9.8)$ \\
\hline Hospitalization time (days) & $9.8 \pm 7.9^{*}$ & $10.3 \pm 6.2^{*}$ & $8.9 \pm 4.6^{*}$ & $7.7 \pm 2.6$ & $7.6 \pm 4.3$ \\
\hline
\end{tabular}

Values presented as means \pm SD or percentage of subjects. $A R B=$ angiotensin receptor blockers; $C A B G=$ coronary artery by-pass grafting; $D M=$ type 2 diabetes mellitus; GFR = glomerular filtration rate; GP Ilb/lla = glycoprotein Ilb/Illa; IGT = impaired glucose tolerance; IFG = impaired fasting glucose; NGT = normal glucose tolerance; IRA = infarct-related artery; $\mathrm{PCl}=$ percutaneous coronary intervention; $\mathrm{TIMI}=$ Thrombolysis in Myocardial Infarction

* - p value $<0.05$ compared with normal glucose tolerance group (NGT). 
Table 2 Comparative analysis of the outcomes between study groups

\begin{tabular}{|c|c|c|c|c|c|}
\hline & $\mathrm{DM}(\mathrm{n}=425)$ & New onset DM $(n=384)^{a}$ & IGT $(n=560)^{b}$ & IFG $(n=376)^{c}$ & NGT $(n=782)^{d}$ \\
\hline \multicolumn{6}{|l|}{ 30-day outcome: } \\
\hline Myocardial infarction - no. (\%) & $4(1.0)$ & $5(1.3)$ & $10(1.8)$ & $6(1.7)$ & $13(1.7)$ \\
\hline PCl - no. (\%) & $16(3.7)^{b}$ & $6(1.6)$ & $7(1.3)$ & $9(2.4)$ & $18(2.3)$ \\
\hline CABG - no. (\%) & $0(0)$ & $4(1.0)^{d}$ & $4(0.7)^{d}$ & $1(0.3)$ & $0(0.0)$ \\
\hline Stroke - no. (\%) & $1(0.2)$ & $1(0.3)$ & $1(0.2)$ & $2(0.5)$ & $2(0.3)$ \\
\hline Mortality - no. (\%) & $9(2.1)$ & $3(0.8)$ & $6(1.0)$ & $2(0.5)$ & $9(1.1)$ \\
\hline MACE - no. (\%) & $28(6.6)^{c d}$ & $15(4.0)$ & $23(4.1)$ & $12(3.2)$ & $26(3.3)$ \\
\hline \multicolumn{6}{|l|}{ 1-year outcome: } \\
\hline Myocardial infarction - no. (\%) & $63(14.8)$ & $42(11.0)$ & $86(15.3)$ & $59(15.8)$ & $106(13.6)$ \\
\hline $\mathrm{PCl}$ - no. (\%) & $90(21.2)^{b}$ & $72(18.8)$ & $86(15.3)$ & 70 (18.6) & $129(16.5)$ \\
\hline CABG - no. (\%) & $41(9.6)$ & $32(8.3)$ & $54(9.7)$ & $41(10.9)$ & $64(8.2)$ \\
\hline Stroke - no. (\%) & $7(1.6)$ & $9(2.3)^{d}$ & $8(1.4)$ & $5(1.3)$ & $5(0.6)$ \\
\hline Mortality - no. (\%) & $38(9.0)^{a c d}$ & $20(5.2)$ & $38(6.7)^{c d}$ & $11(2.9)^{b}$ & $29(3.7)$ \\
\hline MACE - no. (\%) & $174(41.0)^{a c d}$ & $111(29.0)^{b}$ & $208(37.1)^{\text {a c d }}$ & $113(30.0)^{b}$ & $229(29.3)$ \\
\hline \multicolumn{6}{|l|}{ Remote follow up: } \\
\hline Myocardial infarction - no. (\%) & $73(17.2)$ & $51(13.3)$ & $95(17.0)$ & $63(16.8)$ & $128(16.4)$ \\
\hline $\mathrm{PCl}$ - no. (\%) & $108(25.4)^{b}$ & $88(22.9)$ & $103(18.4)$ & $79(21.0)$ & $166(21.2)$ \\
\hline CABG - no. (\%) & $49(11.5)$ & $32(8.3)$ & $55(9.9)$ & $46(12.2)$ & $72(9.2)$ \\
\hline Stroke - no. (\%) & $13(3.1)$ & $12(3.1)$ & $11(2.0)$ & $8(2.1)$ & $11(1.4)$ \\
\hline Mortality - no. (\%) & $52(12.3)^{c d}$ & $37(9.6)^{c d}$ & $53(9.4)^{c d}$ & $21(5.6)^{a b}$ & $50(6.4)$ \\
\hline MACE - no. (\%) & $187(43.9)$ & 153 (39.8) & $227(40.6)$ & $152(40.4)$ & $310(39.7)$ \\
\hline
\end{tabular}

Values presented as percentage of subjects. CABG = coronary artery by-pass grafting; $\mathrm{DM}=$ type 2 diabetes mellitus; IGT = impaired glucose tolerance; $\mathrm{IFG}=$ impaired fasting glucose; $\mathrm{NGT}=$ normal glucose tolerance; $\mathrm{MACE}=$ major adverse cardiovascular event; $\mathrm{PCl}=$ percutaneous coronary intervention . a - p value $<0.05$ compared with new onset DM group.

b $-p$ value $<0.05$ compared with IGT group.

c - p value $<0.05$ compared with IFG group.

d $-p$ value $<0.05$ compared with NGT group.

However, while in a 1-year observation period MACE events were more frequent in DM and IGT groups, during the remote observation there were no significant differences in MACE among all study groups [Table 2]. Cumulative survival rates in study groups with different GA have been presented in Figure 2.

\section{Independent predictors for death}

The multivariate Cox-regression analysis revealed the independent predictors of death in GA patients [Table 3]. The strongest and common independent risk factors for death in both prediabetic and diabetic group were glomerular filtration rate $<60 \mathrm{ml} / \mathrm{min} / 1,73 \mathrm{~m}^{\wedge} 2$ (HR 2.0 and 2.8) and left ventricle ejection fraction $<35 \%$ (HR 2.5 and 1.8 , all $\mathrm{P}<0.05)$ respectively.

\section{Discussion}

Results of several cohort studies revealed that glucose abnormalities other than DM are very frequent in patients with CHD [11], [12] and [13]. The Euro Heart Survey on Diabetes and the Heart showed that the rates of normal glucose tolerance were less common than abnormal ones in patients with diagnosed CHD and that over $50 \%$ of CHD subjects had IGT or newly detected DM [12] and [14]. Our results confirmed the high prevalence of abnormal glucose metabolism in AMI patients, with only $31 \%$ of subjects with normal glucose tolerance and a high proportion of DM, IGT and IFG (32, 22 and $15 \%$ respectively).

Published data indicates also that hyperglycaemia is associated with adverse outcomes regardless of diabetes status [15], [16] and [17]. Stress hyperglycaemia in a setting of AMI increases the risk of malignant ventricular tachyarrhythmias as well as in-hospital mortality [16]. In the observational registry of consecutive nondiabetic patients with STEMI Timmer et al. reported that acute admission hyperglycaemia was associated with increased 1 -year and remote mortality [17]. However, by means of elevated admission glucose as well as $\mathrm{HbA}_{1 \mathrm{c}}$ the authors were able to identify the first parameter as the predictor of early adverse outcomes, while the latter one was independently associated with 1-year and long-term 


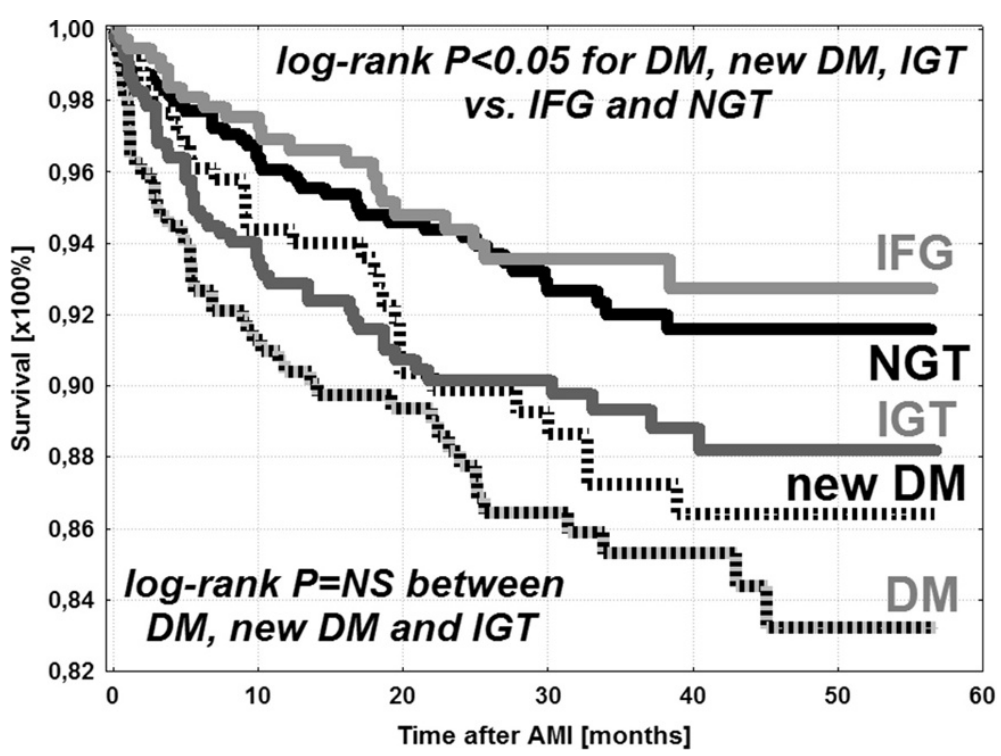

Figure 2 Kaplan-Meier survival curves in particular study groups, NGT - normal glucose tolerance, New DM - newly diagnosed diabetes mellitus, DM - diabetes mellitus diagnosed previously, IGT - impaired glucose tolerance, IFG - impaired fasting glucose, IFG and control group vs IGT, new onset DM and DM; $p<0.05$. IFG vS control group; $p=N S$. IGT vs new onset DM vs DM; $p=N S$. Time in months.

mortality. Similarly, Chan et al. showed that $\mathrm{HbA}_{1 \mathrm{c}}$ concentration in diabetic patients in a setting of acute coronary syndrome is not related to short-term cardiovascular outcome [18].

It is known that patients with both CHD and DM have worse outcomes than subjects with only one of these two conditions [5], [19] and [20]. However, to the best of our knowledge, there is very limited data on the impact of different glucose perturbations on early and late clinical outcomes in AMI patients treated with PCI in the acute phase of myocardial infarction. Lenzen et al. in a population of coronary artery disease showed that patients with previously recognized DM are at highest risk for adverse events, while those with newly detected DM are at intermediate risk. Nevertheless, IFG and IGT were not identified as independent predictors of worse outcome. What is more, acute coronary syndromes accounted for only $36 \%$ of patients in this study [14]. In GAMI study, the analysis of AMI population with coexisting abnormal glucose tolerance revealed that both IGT and newly diagnosed DM are strong and

Table 3 Independent risk factors for death

\begin{tabular}{|c|c|c|c|c|c|c|}
\hline \multirow{2}{*}{$\begin{array}{l}\text { Independent predictors } \\
\text { of death }\end{array}$} & \multicolumn{3}{|c|}{ Prediabetic group } & \multicolumn{3}{|c|}{ Diabetic group } \\
\hline & HR & $95 \% \mathrm{Cl}$ & $\mathrm{p}$ & HR & $95 \% \mathrm{Cl}$ & $\mathbf{p}$ \\
\hline $\mathrm{GFR}<60 \mathrm{ml} / \mathrm{min} / 1,73 \mathrm{~m} \wedge 2$ & 2.03 & $1.43-2.63$ & 0.02 & 2.84 & $2.37-3.31$ & $<0.01$ \\
\hline LVEF <35\% & 2.52 & 1.96-3.08 & $<0.01$ & 1.82 & $1.29-2.35$ & 0.029 \\
\hline Age $>70$ yrs & 2.20 & $1.7-2.7$ & $<0.01$ & 1.39 & $0.92-1.86$ & 0.17 \\
\hline
\end{tabular}

GFR - glomerular filtration rate.

LEVF - left ventricle ejection fraction. independent predictors of adverse cardiovascular events after myocardial infarction [13]. However, of note is that the GAMI population was relatively small and consisted of only 168 subjects. The group with abnormal glucose tolerance included 113 patients not only with IGT, but also with a newly detected DM. What is more, reperfusion therapy had been used only in $38 \%$ of patients with glucose abnormalities and in 51\% with normal glucose regulation.

Our registry encompassed 2527 consecutive inhospital AMI survivors, who were optimally treated, both pharmacologically and invasively (reperfusion by means of PCI only) in the acute phase of AMI. Total mortality rate of $8.6 \%$ in our study was relatively low. However, this may be a result of the study protocol, which was based on the analysis of in-hospital survivors $(n=2527,92.5 \%)$ in order to assess properly the outcomes of AMI patients with different glucose abnormalities, in particular with GA other than previously diagnosed DM. Indeed, it would be impossible to diagnose accurately and reliably GA other than previously diagnosed DM in patients who died during hospitalization. Among 206 subjects with AMI ( $\mathrm{n}=7.5 \%)$ who died during index hospitalization 107 (52\%) subjects had previously diagnosed DM. What is more, all consecutive patients with AMI were treated very homogenously and optimally both pharmacologically and invasively with modern therapy (PCI), in line with ESC recommendations and this may have contributed to the relatively low long-term mortality. 
The main finding of our study is that IGT affects negatively the outcomes of AMI patients treated invasively in the acute phase of myocardial infarction. What is more, the long-term prognosis of patients with IGT is similar to the outcomes of AMI subjects with DM and significantly worse than in normoglycaemic patients. Both, IGT and DM increase significantly one year and remote mortality in AMI population.

Moreover, further multivariate analysis model identified independent predictors of death in subjects with glucose abnormalities. Impaired renal function along with depressed left ventricle ejection fraction appeared to be the strongest and common risk factors for death in both prediabetic and diabetic groups. On a similar study population Kowalczyk et al. found that the prognosis of diabetics with AMI is related to renal function and diabetes coexisting with chronic kidney disease (CKD) is one of the strongest independent risk factors for cardiovascular complications and total mortality [21]. Similarly, Kim et al. in a nationwide prospective Korea Acute Myocardial Infarction Registry (KAMIR) showed that compromised renal function, in particular in combination with diabetes, is associated with the occurrence of composite MACE and indicates poor prognosis in subjects with AMI [22]. The impact of abnormal glucose metabolism on left ventricular function and prognosis in AMI patients was assessed by Høfsten et al. who demonstrated a linear association between GA and left ventricular dysfunction [23]. What is more, Juana A Flores-Le Roux et al. reported that in subjects with acute decompensation of heart failure, a new onset diabetes is not only common, but also increases remote mortality in the same manner as previously diagnosed diabetes [24].

Our results thus confirmed an observation, that large proportion of AMI patients has IGT as well as that this type of abnormal glucose metabolism indicates the group of patients at a high risk of adverse cardiac events. Therefore, interventions which would improve the prognosis in this group of AMI patients should be considered. Published data indicates that smoking cessation, prevention of weight gain, and consumption of low-fat dairy products could substantially lower this risk [6] and [25]. However, although AMI individuals are usually scheduled to follow these recommendations, our results suggest that this type of strategy is insufficient.

Although it has been suggested, that IGT may be a more "benign" state than DM the results of our registry indicate, that both IGT and DM bear poor prognosis in AMI patients [6]. The intriguing convergence of survival Kaplan-Meier curves in diabetic and IGT-patients who survived AMI may be explained by different treatment strategies in both groups. Diabetic patients, in contrast to IGT subjects, receive glucose-lowering medications during acute AMI phase and throughout the follow-up period. Consequently, the beneficial effect of such a pharmacotherapy only in DM subjects could be responsible for similar long-term prognosis in both groups.

Up to date, only a few studies examined the effects of antidiabetic treatment in IGT subjects [25], [26] and [27]. However, the STOPNIDDM trial revealed very optimistic results [25] and [26]. In this randomized, placebo-controlled trial Acarbose - oral anti-diabetic agent, significantly prevented or delayed the progression of glucose intolerance to diabetes and, most importantly, significantly reduced the risk of cardiovascular events. These data provided a strong rationale for the use of similar agents as a part of treatment strategy in AMI patients with coexisting IGT to improve long-term prognosis.

Some recently published trials also indicated that lifestyle modification and various pharmacological agents can delay or prevent the development of glucose disturbances to overt diabetes. However, the expected rates of cardiovascular events in these studies were low and did not provide statistical power to evaluate the influence of such interventions on MACE [28], [29] and [30]. The recently published, promising study in this area was The Navigator trial. The study was designed to evaluate whether reducing postprandial hyperglycaemia and blockade of the renin-angiotensin-aldosterone system or both interventions reduce the risk of diabetes and cardiovascular events in patients with IGT [31]. However, after a median follow up of 6.5 years, neither valsartan nor nateglinide improved cardiovascular prognosis in the study population. What is more, nateglinide did not reduce the risk of new onset diabetes, while valsartan reduced this risk only by $14 \%$ [32] and [33]. The above mentioned conflicting data from different studies indicates the need for further randomized clinical trials in order to establish the position of glucose-lowering agents in prevention of adverse cardiovascular events in AMI patients.

\section{Clinical implications}

Our data confirmed the importance of OGTT performed before hospital discharge in detection of glucose abnormalities in non-diabetic AMI patients. Similarly to diabetic patients, subjects with IGT who survived myocardial infarction treated with PCI in the acute phase have unfavorable long-term prognosis. Further studies are necessary to evaluate the role of new, additional methods of treatment, possibly including glucose lowering agents to improve prognosis in this high-risk group of patients.

\section{Limitation of the study}

This is a single center, observational registry. Differences in baseline characteristics among study groups are a 
result of the registry protocol, which allowed to enroll consecutive in-hospital AMI survivors who were treated with $\mathrm{PCI}$ in the acute phase of myocardial infarction. Neither OGTT was repeated in the follow-up period nor details regarding further hypoglycaemic treatment are available.

\section{Competing interests}

The authors state, that they have read and approved the manuscript, the paper is original, has not been published and is not under simultaneous consideration for publication elsewhere, and none of the authors has any competing interest to disclose.

\section{Authors' contributions}

The corresponding author MM collection of data, and JK conception and design, analysis and interpretation of data, drafting of the manuscript, final approval of the manuscript submitted. RL, LP, KS, and ZK interpretation of data, revising manuscript critically for important intellectual content, final approval of the manuscript submitted. TZ, AS, PSP, SA, BS, OK collection of data, analysis and interpretation of data, final approval of the manuscript submitted. All authors read and approved the final manuscript.

\section{Author details}

'Department of Cardiology, Congenital Heart Diseases and Electrotherapy, Medical University of Silesia, Silesian Center for Heart Diseases, ul. Szpitalna 2, 41-800 Zabrze, Poland. ${ }^{2}$ Third Department of Cardiology, Medical University of Silesia, Silesian Center for Heart Diseases, Zabrze, Poland. ${ }^{3}$ Department of Internal Diseases, Diabetology and Cardiometabolic Diseases, Medical University of Silesia, Silesian Center for Heart Diseases, Zabrze, Poland.

Received: 26 February 2012 Accepted: 12 June 2012

Published: 28 June 2012

\section{References}

1. King H, Aubert RE, Herman WH: Global burden of diabetes 1995-2025. Prevelance, numerical estimates and projections. Diabetes Care 1998, 21(9):1414-1431.

2. Wild S, Roglic G, Green A, Sicree R, King H: Global prevalence of diabetes: estimates for the year 2000 and projections for 2030. Diabetes Care 2004, 27(5):1047-1053

3. King $\mathrm{H}$, Rewers $\mathrm{M}$ : Global estimates for prevalence of diabetes mellitus and impaired glucose tolerance in adults: WHO Ad Hoc Diabetes Reporting Group. Diabetes Care 1993, 16(1):157-177.

4. Mukamal K, Nesto RW, Cohen MC, Muller JE, Maclure M, Sherwood JB, Mittleman MA: Impact of diabetes on long-term survival after acute myocardial infarction: comparability of risk with prior myocardial infarction. Diabetes Care 2001, 24(8):1422-1427.

5. Haffner SM, Lehto S, Rönnemaa T, Pyörälä K, Laakso M: Mortality from coronary heart disease in subjects with type 2 diabetes and in nondiabetic subjects with and without prior myocardial infarction. N Engl J Med 1998, 339(4):229-234.

6. Mozaffarian D, Marfisi R, Levantesi G, Silletta MG, Tavazzi L, Tognoni G, Valagussa F, Marchioli R: Incidence of new-onset diabetes and impaired fasting glucose in patients with recent myocardial infarction and the effect of clinical and lifestyle risk factors. Lancet 2007, 370(9588):667-675.

7. Bartnik M, Malmberg K, Hamsten A, Efendic S, Norhammar A, Silveira A, Tenerz A, Ohrvik J, Rydén L: Abnormal glucose tolerance - a common risk factor in patients with acute myocardial infarction in comparison with population-based controls. J Intern Med 2004, 256(4):288-297.

8. World Health Organization: Report of the WHO Consultation. Definition, diagnosis and classification of diabetes mellitus and its complications. Part 1: diagnosis and classification of diabetes mellitus. Geneva: World Health Organization; 1999

9. McCullough PA, Adam A, Becker CR, Davidson C, Lameire N, Stacul F, Tumlin J, CIN Consensus Working Panel: Epidemiology and Prognostic Implications of Contrast-Induced Nephropathy. Am J Cardiol 2006, 98(6A):5K-13K

10. Malmberg K, Rydén L, Efendic S, Herlitz J, Nicol P, Waldenström A, Wedel H, Welin $L: A$ randomised trial of insulin-glucose infusion followed by subcutaneous insulin treatment in diabetic patients with acute myocardial infarction (DIGAMI study): effects on one year mortality. J Am Coll Cardiol 1995, 26(1):57-65.

11. Norhammar A, Tenerz A, Nilsson G, Hamsten A, Efendíc S, Rydén L, Malmberg K: Glucose metabolism in patients with acute myocardial infarction and no previous diagnosis of diabetes mellitus: a prospective study. Lancet 2002, 359(9324):2140-2144.

12. Bartnik M, Rydén L, Ferrari R, Malmberg $K$, Pyörälä $K$, Simoons $M$, Standl $E$, Soler-Soler J, Ohrvik J, Euro Heart Survey Investigators: The prevalence of abnormal glucose regulation in patients with coronary artery disease across Europe. The Euro Heart Survey on diabetes and the heart. Eur Heart J 2004, 25(21):1880-1890.

13. Bartnik M, Malmberg K, Norhammar A, Tenerz A, Öhrvik J, Rydén L: Newly detected abnormal glucose tolerance: an important predictor of long-term outcome after myocardial infarction. Eur Heart J 2004, 25(22):1990-1997.

14. Lenzen M, Ryden L, Öhrvik J, Bartnik M, Malmberg K, Scholte Op Reimer W Simoons ML, Euro Heart Survey Investigators: Diabetes known or newly detected, but not impaired glucose regulation, has a negative influence on 1-year outcome in patients with coronary artery disease: a report from the Euro Heart Survey on diabetes and the heart. Eur Heart J 2006, 27(24):2969-2974.

15. Biteker M, Dayan A, Can MM, Illhan E, Biteker FS, Tekkeșin A, Duman D: Impaired fasting glucose is associated with increased perioperative cardiovascular event rates in patients undergoing major noncardiothoracic surgery. Cardiovasc Diabetol 2011, 10:63.

16. Sanjuán R, Núñez J, Blasco ML, Miñana G, Martínez-Maicas H, Carbonell N, Palau P, Bodí V, Sanchis J: Prognostic implications of stress hyperglycemia in acute ST elevation myocardial infarction. Prospective observational study. Rev Esp Cardiol 2011, 3:201-207.

17. Timmer JR, Hoekstra M, Nijsten MW, van der Horst IC, Ottervanger JP, Slingerland RJ, Dambrink JH, Bilo HJ, Zijlstra F, van 't Hof AW: Prognostic value of admission glycosylated hemoglobin and glucose in nondiabetic patients with ST-segment-elevation myocardial infarction treated with percutaneous coronary intervention. Circulation 2011, 124(6):704-711.

18. Chan CY, Li R, Chan JY, Zhang Q, Chan CP, Dong M, Yan BP, Lam YY, Yu $\mathrm{CM}$ : The value of admission $\mathrm{HbA}(1 \mathrm{c})$ level in diabetic patients with acute coronary syndrome. Clin Cardiol 2011, 34(8):507-512.

19. Donahoe SM, Stewarrt GC, McCabe CH, Mohanavelu S, Murphy SA, Cannon CP, Antman EM: Diabetes and mortality following acute coronary syndrome. JAMA 2007, 298(7):765-775.

20. Hu FB, Stampfer MJ, Solomon CG, Liu S, Willett WC, Speizer FE, Nathan DM, Manson JE: The impact of diabetes mellitus on mortality from all causes and coronary heart disease in women: 20 years of follow-up. Arch Intern Med 2001, 161(14):1717-1723.

21. Kowalczyk J, Lenarczyk R, Strojek K, Zielinska T, Gumprecht J, Sedkowska A Kukulski T, Swierad M, Kowalski O, Sredniawa B, Polonski L, Zembala M, Kalarus Z: Prognosis in diabetic patients with acute myocardial infarction treated invasively is related to renal function. Med Sci Monit 2010, 16(2):67-74

22. Kim CS, Choi JS, Park JW, Bae EH, Ma SK, Jeong MH, Kim YJ, Cho MC, Kim CJ, Kim SW: Korea Acute Myocardial Infarction Registry Investigators: Concomitant renal insufficiency and diabetes mellitus as prognostic factors for acute myocardial infarction. Cardiovasc Diabetol 2011, 31:95.

23. Høfsten DE, Løgstrup BB, Møller JE, Pellikka PA, Egstrup K: Abnormal glucose metabolism in acute myocardial infarction: influence on left ventricular function and prognosis. JACC Cardiovasc Imaging 2009, 5:592-599.

24. Flores-Le Roux JA, Comin J, Pedro-Botet J, Benaiges D, Puig-de Dou J, Chillarón JJ, Goday A, Bruguera J, Cano-Perez JF: Seven-year mortality in heart failure patients with undiagnosed diabetes: an observational study. Cardiovasc Diabetol 2011, 10:39.

25. Zeymer U, Schwarzmaier-D'assie A, Petzinna D, Chiasson JL, STOP-NIDDM Trial Research Group: Effect of acarbose treatment on the risk of silent myocardial infarction in patients with impaired glucose tolerance. Results of the randomized STOP-NIDDM trial ECG substudy. Eur 」 Cardiovasc Prev Rehabil 2004, 11(5):412-415.

26. Chiasson JL, Josse RG, Gomis R, Hanefeld M, Karasik A, Laakso M, STOPNIDDM Trial Research Group: Acarbose treatment and the risk of cardiovascular disease and hypertension in patients with impaired glucose tolerance: the STOP-NIDDM trial. JAMA 2003, 290(4):2072-2077.

27. Zeymer U: Cardiovascular benefits of acarbose in impaired glucose tolerance and type 2 diabetes. Int J Cardiol 2006, 107(1):11-20. 
28. Tuomilehto J, Lindström J, Eriksson JG, Valle TT, Hämäläinen $\mathrm{H}$, llanneParikka P, Keinänen-Kiukaanniemi S, Laakso M, Louheranta A, Rastas M, Salminen V, Uusitupa M: Finnish Diabetes Prevention Study Group: Prevention of type 2 diabetes mellitus by changes in lifestyle among subjects with impaired glucose tolerance. N Eng J Med 2001, 344(18):1343-1350.

29. Knowler WC, Barrett-Connor E, Fowler SE, Hamman RF, Lachin JM, Walker EA, Nathan DM: Diabetes Prevention Program Research Group: Reduction in the incidence of type 2 diabetes with lifestyle intervention or metformin. N Eng J Med 2002, 346(6):393-403.

30. Ratner R, Goldberg R, Haffner S, Marcovina S, Orchard T, Fowler S, Temprosa M: Diabetes Prevention Program Research Group: Impact of intensive lifestyle and metformin therapy on cardiovascular disease risk factors in the diabetes prevention program. Diabetes Care 2005, 28(4):888-894.

31. Califf RM, Boolell M, Haffner SM, Bethel MA, McMurray J, Duggal A, Holman RR, NAVIGATOR Study Group: Prevention of diabetes and cardiovascular disease in patients with impaired glucose tolerance: rationale and design of the nateglinide and valsartan in impaired glucose tolerance outcomes research (NAVIGATOR) trial. Am Heart J 2008, 156(4):623-632.

32. Holman RR, Haffner SM, McMurray JJ, Bethel MA, Holzhauer B, Hua TA, Belenkov Y, Boolell M, Buse JB, Buckley BM, Chacra AR, Chiang FT, Charbonnel B, Chow CC, Davies MJ, Deedwania P, Diem P, Einhorn D, Fonseca V, Fulcher GR, Gaciong Z, Gaztambide S, Giles T, Horton E, Ilkova H, Jenssen T, Kahn SE, Krum H, Laakso M, Leiter LA, NAVIGATOR Study Group: Effect of nateglinide on the incidence of diabetes and cardiovascular events. N Engl J Med 2010, 362(16):1463-1476.

33. McMurray JJ, Holman RR, Haffner SM, Bethel MA, Holzhauer B, Hua TA, Belenkov Y, Boolell M, Buse JB, Buckley BM, Chacra AR, Chiang FT, Charbonnel B, Chow CC, Davies MJ, Deedwania P, Diem P, Einhorn D, Fonseca V, Fulcher GR, Gaciong Z, Gaztambide S, Giles T, Horton E, Ilkova H, Jenssen T, Kahn SE, Krum H, Laakso M, Leiter LA, NAVIGATOR Study Group: Effect of valsartan on the incidence of diabetes and cardiovascular events. N Engl J Med 2010, 362(16):1477-1490.

doi:10.1186/1475-2840-11-78

Cite this article as: Mazurek et al:: The prognostic value of different glucose abnormalities in patients with acute myocardial infarction treated invasively. Cardiovascular Diabetology 2012 11:78.

\section{Submit your next manuscript to BioMed Central and take full advantage of:}

- Convenient online submission

- Thorough peer review

- No space constraints or color figure charges

- Immediate publication on acceptance

- Inclusion in PubMed, CAS, Scopus and Google Scholar

- Research which is freely available for redistribution 